\title{
Differences of Ampicillin and Cefazolin Effects in Reducing hs- CRP Level in Premature Rupture of Membranes
}

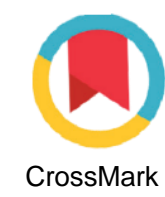

\author{
Ahmad Bukhoeri ${ }^{1}$, Syarief Thaufik Hidayat ${ }^{1}$, Ediwibowo Ambari ${ }^{1}$, Julian Dewantiningrum ${ }^{1}$, \\ Putri Sekar Wiyati ${ }^{1}$, Besari Adi Pramono ${ }^{1 *}$
}

${ }^{1}$ Department of Obstetrics and Gynaecology, Faculty of Medicine, Diponegoro University/Dr Kariadi General Hospital Medical Center, Semarang, Central Java, Indonesia

Keywords:
Ampicillin
Cefazolin
hs-CRP level
Premature rupture of
membranes

*) Correspondence to: besariadi@fk.undip.ac.id

Article history:

Received 07-07-2020

Accepted $08-12-2020$

Availableonline10-03-2021

\begin{abstract}
Background: Premature rupture of membranes (PROM) is a rupture of amniotic sac before delivery. PROM is associated with an increased incidence of preterm labor and infection. The use of prophylactic antibiotic may reduce the risks of infection. High-sensitivity C-reactive protein (hs-CRP) is an acute-phase reactant protein that is associated with PROM. How much effect of prophylactic antibiotic to hs-CRP level remains unclear.

Objective: To compare the reduction in hs-CRP levels in premature rupture of membranes before and after given ampicillin or cefazolin.

Methods: The design of this study was true experimental design (pre and post-test) conducted at Dr. Kariadi General Hospital Medical Center Semarang and Kartini General Hospital Jepara from September 2019 to January 2020. Study samples are pregnant women with premature rupture of membranes that came to the Emergency Department and Maternity Ward Dr. Kariadi General Hospital Medical Center Semarang and Kartini General Hospital Jepara. Samples were divided into two groups, a group treated with ampicillin and the other with cefazolin therapy. All samples were subjected to a hs-CRP examination. Statistical analysis was performed by Mann-Whitney and Wilcoxon.

Results: There are no significant differences in the age variable (28.8 \pm 6.54 vs 29.1 $\pm 5.93)$, gestational age $(36.3 \pm 2.55$ vs $36.3 \pm 2.90)$, and parity $(2,2 \pm 0.99$ vs $2.47 \pm$ $1.19)$ in the ampicillin and cefazolin groups ( $p>0.05)$. In this study, $37.1 \%$ patients have a history of PROM while $62.9 \%$. had no history of PROM. Reduction in hsCRP levels after administration of ampicillin and cefazolin was significant (4.4 \pm $2.65 \mathrm{mg} / \mathrm{L}$ vs $6.3 \pm 4.43 \mathrm{mg} / \mathrm{L}$, respectively, $\mathrm{p}=0.03)$. The difference in the decrease in hs-CRP levels before and after given ampicillin and cefazolin was significant ( $\mathrm{p}=$ $0.0001)$.

Conclusion: There is a decrease in hs-CRP levels after the administration of ampicillin or cefazolin in PROM, whereas cefazolin induced higher reduction in hsCRP levels. Ampicillin can still be used as a first-line prophylactic antibiotic in primary healthcare facilities.
\end{abstract}

DIMJ, 2021, 2(1), 1-5 DOI: https:// doi.org/10.14710/dimj.v2i1.8428

\section{Introduction}

Premature rupture of membranes (PROM) is defined as the rupture of the membranes before delivery. PROM can occur at or after 37 weeks' gestation or before 37 weeks' gestation (PPROM or preterm premature rupture of membranes). ${ }^{1}$ Under normal circumstances, $8-10 \%$ of women in a term pregnancy will experience PROM. ${ }^{2}$

At present, the problem of PROM requires more attention because of its high prevalence, and the incidence of infection tends to increase. The prevalence of term PROM occurs in approximately $6.46-15.6 \%$ of term pregnancies, and PPROM occurs in about $2-3 \%$ of all single pregnancies and $7.4 \%$ of twin pregnancies. PROM incidence in Indonesia ranges from $4.5-6 \%$. Several studies found that patients experienced chorioamnionitis when hs-CRP levels were examined for the highest levels. Besides, there is a high level of maternal serum CRP $(>20,000 \mu \mathrm{g} / \mathrm{l})$ in patients with premature rupture of membranes when admitted to 
the hospital as an early marker that indicates funicitis with good diagnostic performance. ${ }^{6}$

Antibiotic therapy is recommended by many case studies of premature rupture of membranes since PROM can increase neonatal complications..$^{711} \mathrm{~A}$ research shows that the use of antibiotics for PPROM can prevent $4 \%$ of neonatal deaths. Some commonly used antibiotics are erythromycin or amoxicillin/ clavulanic acid or cefazolin. ${ }^{7}$ Ampicillin with or without erythromycin is recommended for PPROM. ${ }^{12}$

In PNPK (National Guidelines for Medical Services), it is suggested that ampicillin can still be used as a prophylactic antibiotic in premature rupture of membranes, while in Dr. Kariadi General Hospital Medical Center, they use cefazolin as prophylaxis. On the other hand, the use of ampicillin is more efficient than cefazolin. Ampicillin is more readily available in primary health facilities and cheaper. Therefore, the authors intend to research on the administration of ampicillin compared to cefazolin to reduce hs-CRP levels in PROM.

\section{Method}

The design of this study was a true experimental design study (pre and post-test design), conducted at Dr. Kariadi General Hospital Medical Center in Semarang and Kartini General Hospital in Jepara from September 2019 until January 2020. The study samples were pregnant women with premature rupture of membranes in the Emergency Department and Maternal Ward of Dr. Kariadi Hospital Semarang and Kartini Hospital Jepara, which met the inclusion criteria (primigravida and multigravida with gestational age $\geq 20$ weeks, and a single fetus living intrauterine). Patients with a history of cardiovascular abnormalities, history of chronic hypertension, diabetes mellitus, kidney disease, chronic and systemic infections, smoking habits, drinking alcoholic beverages, use of drugs containing estrogen and progesterone during pregnancy, obesity, intrauterine fetal death, and antepartum haemorrhage were excluded from the study.

Samples were selected using a randomization block. Data from all samples were obtained through history taking, physical examination, and laboratory examination as indicated and divided into two groups: group I who was given ampicillin therapy with a dose of 2 grams intravenously and group II who was given cefazolin therapy with a dose of 2 grams intravenously. The patients' venous blood sample was obtained through a $5 \mathrm{cc}$ medial cubital vein. Serum hs-CRP levels were measured with the Latex Turbidimetry Immunoassay (LTIA) method before and 6 hours after administration of ampicillin or cefazolin in both groups.

Statistical analysis was performed using the Shapiro-Wilk test to assess the distribution of primary data, the analysis of hs-CRP levels using the Mann-Whitney test. Wilcoxon test was used in differences in the decrease of hs-CRP levels before and after administration.

\section{Results}

This study was conducted from September 2019 to January 2020. Seventy (70) subjects were recruited, consisting of 35 subjects in each group of ampicillin and cefazolin. As shown in Table 1, there is no significant difference in the age variable $(28.8 \pm$ 6.54 vs $29.1 \pm 5.93)$, gestational age $(36.3 \pm 2.55$ vs $36.3 \pm 2.90)$, and parity $(2,2 \pm 0.99$ vs $2.47 \pm 1.19)$ in the ampicillin and cefazolin groups ( $p>0.05$ ). In this study, $37.1 \%$ patients have a history of PROM while those with no history of PROM are 62.9\%.

Table 1. Subject Characteristics

\begin{tabular}{|c|c|c|c|}
\hline \multirow[b]{2}{*}{ Characteristics } & \multicolumn{2}{|c|}{ Antibiotic Type } & \multirow[b]{2}{*}{$\mathrm{P}$} \\
\hline & $\begin{array}{l}\text { Ampicillin } \\
(\mathrm{n}=35)\end{array}$ & $\begin{array}{l}\text { Cefazolin } \\
(\mathrm{n}=35)\end{array}$ & \\
\hline Age (years) & $\begin{array}{l}28,8 \pm 6,54 \\
30,0(17-41)\end{array}$ & $\begin{array}{l}29,1 \pm 5,93 \\
30,0(17-39)\end{array}$ & 0,849 \\
\hline $\begin{array}{l}\text { Gestational age } \\
\text { (weeks) }\end{array}$ & $\begin{array}{l}36,3 \pm 2,55 \\
37,0(29-40)\end{array}$ & $\begin{array}{l}36,3 \pm 2,90 \\
37,0(29-40)\end{array}$ & 0,877 \\
\hline Parity & $\begin{array}{l}2,2 \pm 0,99 \\
2,0(1-5)\end{array}$ & $\begin{array}{l}2,47 \pm 1,19 \\
2,0(1-5)\end{array}$ & 0,695 \\
\hline PROM History & & & \\
\hline Yes & $13(37,1 \%)$ & $13(37,1 \%)$ & 1,000 \\
\hline No & $22(62,9 \%)$ & $22(62,9 \%)$ & \\
\hline
\end{tabular}

Table 2 shows that there are significant differences in hs-CRP levels before giving ampicillin and cefazolin $(\mathrm{p}=0.005)$. Differences in the reduction in hs-CRP levels before and after the administration of ampicillin using Wilcoxon test showed significant results $(p=0.0001)$, and differences in the decrease of hs-CRP levels before and after cefazolin also showed significant results $(\mathrm{p}=0.0001)$. Also, no significant difference was found in the difference in levels of hsCRP when given ampicillin compared to cefazolin $(\mathrm{p}=0.054)$ using Mann-Whitney test. 
Table 2. Analysis of hs-CRP levels

\begin{tabular}{lccc}
\hline hs- & \multicolumn{2}{c}{ Antibiotic Type } & \\
CRP & Ampicillin & Cefazolin & \\
Levels & $(\mathrm{n}=35)$ & $(\mathrm{n}=35)$ & \\
\cline { 2 - 3 } Pre & $6,5 \pm 3,57 ; 5,6$ & $10,5 \pm 6,53 ; 7,3$ & 0,005 \\
& $(1,9-17,8)$ & $(2,0-31,8)$ & \\
Post & $4,4 \pm 2,65 ; 3,5$ & $6,3 \pm 4,43 ; 4,8$ & \multirow{2}{*}{0,033} \\
& $(1,1-11,2)$ & $(1,6-20,8)$ & \\
$\mathrm{p}$ & 0,0001 & 0,0001 & \\
$\Delta$ hs- & $2,1 \pm 1,45 ; 1,9$ & $4,2 \pm 3,85 ; 3,2$ & 0,054 \\
CRP & $(0,3-6,6)$ & $(0,1-13,5)$ & \\
\hline * Data is not normally distributed $(\mathrm{p}<0.05)$ &
\end{tabular}

\section{Discussion}

Premature rupture of membranes (PROM) is the rupture of the membranes before labor. PROM can occur at or after 37 weeks 'gestation (PROM or premature rupture of membranes), before 37 weeks' gestation (PPROM or preterm rupture of membranes). ${ }^{1}$

The cause of PROM remains uncertain. History of PROM in a previous pregnancy, genital tract infection, antepartum haemorrhage, and smoking have a very close relationship with the incidence of PROM. ${ }^{13}$ In this study, a history of PROM was observed in $37.1 \%$ of the samples. This figure is similar with other studies which stated that previous history of PROM is a risk factor for the occurrence of PROM by $33.8 \% .{ }^{14}$ History of PROM which is a risk factor for the incidence of PROM may be due to genital infection and urinary tract that is not treated/ asymptomatic, short cervical length, as well as presence of other obstetric problems underlying the PROM. ${ }^{14}$

The levels of hs-CRP will increase with the presence of infections, and the inflammation induced by IL-6 as a result of the antigen-antibody mechanism. ${ }^{15}$ Previous research stated that an increase in serum hs-CRP levels in pregnant women affects the occurrence of low birth weight in infants, intrauterine infection, and causes prematurity. ${ }^{16}$ The occurrence of premature rupture of membranes is mostly related to the presence of infection. Previous studies found that hs-CRP concentrations $>20 \mathrm{mg} / \mathrm{l}$ correlated with the occurrence of chorioamnionitis in women with PROM. ${ }^{17}$ In this study, the mean hs-CRP level in premature rupture of membranes before ampicillin was $6.5 \mathrm{mg} / \mathrm{L}$ and cefazolin $10,5 \mathrm{mg} / \mathrm{L}$, and no clinical chorioamnionitis was found.

Currently, the problem of PROM requires closer attention because it correlates significantly with the increasing incidence of infection. Chorioamnionitis is a complication of $30-40 \%$ of cases of pregnancy with PROM that can cause sepsis in the mother.
However, complications from PROM are not uncommon if treated promptly with appropriate interventions, by administering prophylactic antibiotics among others. Prophylactic antibiotics aim is to reduce the frequency of maternal and fetal infections and thereby delay the onset of preterm labor by extending the latent period. ${ }^{2,4}$

Indonesia's recommendations regarding antibiotic therapy for pregnant patients with PROM have been listed in the National Guidelines for Medical Services (PNPK). It is recommended to administer penicillin (Ampicillin) or macrolide (Erythromycin) antibiotics in parenteral and/or oral form. However, it is still unknown whether the routine use of antibiotic treatment for PROM in term or near term pregnancies is useful., ${ }^{1,18}$ The available research data are lacking to determine the best antibiotic regimen (the type of antibiotic, dose, and duration) to be given in the case of PROM. Nevertheless, the American College of Obstetrics and Gynaecology (ACOG) recommends prophylactic antibiotics to extend the length of the latent period in PROM with a gestational age of less than 34 weeks. ${ }^{19}$ Research conducted in Turkey stated that the use of a 1-gram intravenous dose of cefazolin for PROM prophylaxis could reduce hs-CRP levels. ${ }^{20}$ In this study, the administration of ampicillin and cefazolin can reduce levels of hs-CRP $(\mathrm{p}<0.05)$. During this study, samples did not suffer from any allergies or other complications from the administered prophylactic antibiotics. Ampicillin may still be recommended in premature rupture of membranes, although cefazolin administration can further reduce hs-CRP levels.

The study has some limitations. Other risk factors were not assessed for the incidence of PROM in terms of BMI, the effect of genital infection, cervical length, and previous history of polyhydramnions. The PROM onset was not controlled which might affect hs-CRP levels before administration of antibiotics.

\section{Conclusion}

The level of hs-CRP decreases after the administration of ampicillin or cefazolin in PROM, where cefazolin induced higher reduction in hs-CRP levels compared to ampicillin. Ampicillin can still be used as a first-line prophylactic antibiotic in primary healthcare facilities.

\section{Ethical Approval}

Ethics approval was granted by Ethical Committee of Research and Development (KEPK) of Dr. Kariadi General Hospital Medical Centre 
Semarang with number No.345/EC/KEPKRSDK/2019. All participants have signed a consent form informing them about the study, confidentiality, anonymity, and right to withdraw at any time during the study.

\section{Conflicts of Interest}

The authors declare that they have no competing interests. that may be perceived as inappropriately influencing the representation or interpretation of reported research results.

\section{Funding}

This study was self-funded by the corresponding author. Therefore, there isn't any conflict of interest presented in this study.

\section{Author Contributions}

All of the authors developed the plan and design of the study together. Conceptualization, AB, STH, EA, JD, PSW, BAP; methodology, AB, BAP; software, validation, formal analysis, investigation, $\mathrm{AB}$; resources, $\mathrm{AB}, \mathrm{STH}, \mathrm{EA}, \mathrm{JD}, \mathrm{PSW}, \mathrm{BAP}$; writing - original draft preparation, $\mathrm{AB}$; writingreview and editing, $\mathrm{AB}, \mathrm{STH}, \mathrm{EA}, \mathrm{JD}, \mathrm{PSW}, \mathrm{BAP}$; visualization, $\mathrm{AB}$; supervision, $\mathrm{STH}, \mathrm{EA}, \mathrm{JD}, \mathrm{PSW}$, BAP; project administration, $A B$; funding acquisition $\mathrm{AB}, \mathrm{STH}, \mathrm{EA}, \mathrm{JD}, \mathrm{PSW}, \mathrm{BAP}$.

\section{Acknowledgments}

We are grateful to all patients who came from Dr. Kariadi General Hospital Medical Center Semarang and Kartini General Hospital Jepara.

\section{References}

1. Maternal HKFM. Pedoman Nasional Pelayanan Kedokteran: Ketuban Pecah Dini. Jakarta: Perkumpulan Obstetri dan Ginekologi Indonesia; 2016.

2. Practice Bulletin No. 160: Premature Rupture of Membranes. Obstet Gynecol. 2016;127(1):e3951.

3. Wulandari VE, Pramono BA. Faktor yang mempengaruhi kasus persalinan di UGD RSUP Dr. Kariadi. JKD. 2016; 5(2).

4. Kacerovsky M, Musilova I, Khatibi A, Skogstrand K, Hougaard DM, Tambor V, et al. Intraamniotic inflammatory response to bacteria: analysis of multiple amniotic fluid proteins in women with preterm prelabor rupture of membranes. J Matern Fetal Neonatal Med. 2012;25(10):2014-9.

5. Stepan M, Cobo T, Musilova I, Hornychova H, Jacobsson B, Kacerovsky M. Maternal Serum C-Reactive Protein in Women with Preterm Prelabor Rupture of Membranes. PLoS One. 2016;11(3):e0150217.

6. Perrone G, Anceschi MM, Capri O, Galoppi P, Pizzulo S, Buccheri M, et al. Maternal Creactive protein at hospital admission is a simple predictor of funisitis in preterm premature rupture of membranes. Gynecol Obstet Invest. 2012;74(2):95-9.

7. Tchirikov M, Schlabritz-Loutsevitch N, Maher J, Buchmann J, Naberezhnev Y, Winarno AS, et al. Mid-trimester preterm premature rupture of membranes (PPROM): etiology, diagnosis, classification, international recommendations of treatment options and outcome. J Perinat Med. 2018;46(5):465-88.

8. Yudin MH, van Schalkwyk J, Eyk NV, Infectious Diseases C, Maternal Fetal Medicine C. Antibiotic therapy in preterm premature rupture of the membranes. J Obstet Gynaecol Can. 2009;31(9):863-7.

9. Chauleur C, Rochigneux S, Seffert P, Chene G, Billiemaz K, Collet F. Neonatal outcomes and four-year follow-up after spontaneous or iatrogenic preterm prelabor rupture of membranes before 24 weeks. Acta Obstet Gynecol Scand. 2009;88(7):801-6.

10. Chaemsaithong P, Romero R, Korzeniewski SJ, Martinez-Varea A, Dong Z, Yoon BH, et al. A point of care test for interleukin-6 in amniotic fluid in preterm prelabor rupture of membranes: a step toward the early treatment of acute intraamniotic inflammation/infection. J Matern Fetal Neonatal Med. 2016;29(3):360-7.

11. Xiao C, Gangal M, Abenhaim HA. Effect of magnesium sulfate and nifedipine on the risk of developing pulmonary edema in preterm births. $J$ Perinat Med. 2014;42(5):585-9.

12. Callahan T, Caughey AB. Blueprints obstetrics and gynecology: Lippincott Williams \& Wilkins; 2013.

13. Greene MF, Creasy RK, Resnik R, Iams JD, Lockwood CJ, Moore T. Creasy and Resnik's Maternal-Fetal Medicine: Principles and Practice E-Book: Elsevier Health Sciences; 2008.

14. Assefa Assefa, N., Berhe, H., Girma, F. et al. Risk factors of premature rupture of membranes in public hospitals at Mekele city, Tigray, a case control study. BMC Pregnancy Childbirth. $2018 ; 18,386$. 
15. Maguire PJ, Power KA, O'Higgins AC, Jackson $\mathrm{S}$, Harley R, le Roux CW, et al. Maternal Creactive protein in early pregnancy. Eur J Obstet Gynecol Reprod Biol. 2015;193:79-82.

16. Gahlot K, Pandey K, Singh PP, Gahlot V, Mourya. To evaluate diagnostic efficacy of maternal serum C-reactive protein to predict preterm labour. Int J Reprod Contracept Obstet Gynecol. 2016;5(11):4001-4.

17. Trochez-Martinez R, Smith P, Lamont R. Use of C-reactive protein as a predictor of chorioamnionitis in preterm prelabour rupture of membranes: a systematic review. BJOG. 2007;114(7):796-801.

18. Seelbach-Goebel, B. Antibiotic Therapy for Premature Rupture of Membranes and Preterm Labor and Effect on Fetal Outcome. Geburtshlife Und Frauenheilkunde. 73(12), 1218-1227. 2013. Doi:10.1055/s-003-1360195.

19. Ehsanipoor R. Practice Bulletin No. 160: Premature Rupture of Membranes. ACOG. 127(1):e39-e51, January 2016.

20. Kahyaoğlu S, Timur H, Eren R, Kahyaoğlu I, Eyi EG, Engin-Üstün Y. Can maternal serum Creactive protein levels predict successful labour induction with intravenous oxytocin in term pregnancies complicated with premature rupture of the membranes? A cross-sectional study. $J$ Turk Ger Gynecol Assoc. 2014;15(1):36-40. 